\title{
Knowledge and attitudes of early childhood development practitioners towards hearing health in poor communities
}

\author{
Authors \\ Shouneez Yousuf Hussein ${ }^{1}$ \\ De Wet Swanepoel ${ }^{1}$ \\ Leigh Biagio de Jager ${ }^{1}$ \\ Faheema Mahomed-Asmail ${ }^{1}$
}

\section{Affiliations}

1. Department of Speech-Language Pathology and Audiology, University of Pretoria, Lynwood Road, Pretoria, 0001, South Africa

\author{
Conflicts of interest \\ None
}

\author{
Corresponding author \\ Shouneez Yousuf Hussein \\ Department of Speech-Language Pathology and Audiology, \\ University of Pretoria, Lynwood Road, Pretoria, 0001 \\ Email: shouneezyousuf@gmail.com \\ Tel: +27 726349906
}

\begin{abstract}
Objective: Within the educational sector of low- and middle- income countries (LMICs), formal and informal early childhood development (ECD) centers are often the first point of contact for majority of children. Since early hearing detection services are mostly absent in LMICs, these ECD centers may serve as the first point of access to screenings for these children. ECD practitioner awareness regarding hearing and hearing loss is essential for the successful implementation of hearing screening programs. This study thus investigated
\end{abstract}


the current knowledge and attitudes of ECD practitioners towards childhood hearing loss in a community representative of typical LMIC contexts.

Method: Purposive sampling was used to identify ECD centers and participants across a community. Thereafter, a cross-sectional quantitative survey (82 items) was adminstered amongst 82 ECD practitioners.

Results: More than $80 \%$ of ECD practitioners correctly identified genetics and ear infections as etiological factors of hearing loss. Gaps in knowledge regarding identification techniques for children 3-6 years of age and the impact of hearing loss in the classroom were evident. ECD personnel's duration of experience had a significant effect on overall knowledge and attitude $(p<0.05 ; F(1,53)=8.68)$. ECD personnel displayed a positive attitude towards children receiving a hearing test (88.3\%) and almost all participants indicated the need for more information regarding hearing loss (93.5\%).

Conclusions: This study demonstrated a general readiness amongst ECD practitioners for the implementation of ECD hearing screening programs in LMICs, however additional information and guidelines are needed to improve practitioner knowledge and attitudes.

\section{Keywords}

Knowledge, attitudes, questionnaire, low- and middle- income countries (LMICs), early childhood development (ECD), practitioner.

\section{Introduction}

Hearing loss is one of the most common developmental disorders identifiable at birth which, if left undetected, has consequences on a child's language development, communication ability, educational attainment, vocational achievement and social-emotional development [1,2,3]. The most effective way to avoid these negative consequences is through the establishment of early hearing detection and intervention (EHDI) programs such as newborn hearing screening (NHS) programs [4]. However, such programs are often unavailable to babies born within low- and middle-income countries (LMICs). In LMICs like South Africa, EHDI programs are limited due to socio-economic and heath care barriers, limited contextual research evidence, and a lack of 
financial and human resources [5,6,7]. The result is that a large proportion of children are still unidentified at the time of school entry, thus increasing a child's risk for failure and drop-out from school $[3,8,9]$.

Within LMICs such as South Africa, emphasis has been placed on the early identification of children with disabilities through the legislative requirement of promoting early childhood development (ECD) [10]. ECD centres are aimed at providing emotional, cognitive and physical development of children from birth to school going age [10]. These ECD centers have the potential to serve as the first point of access to preventative hearing health care to children who were not screened at birth, or who acquired a childhood hearing loss hereafter. A study by Eiserman, et al. [11] conducted in the US demonstrated that implementing hearing screenings in early childhood programs can help to identify a wide range of hearing health conditions that can potentially disrupt language acquisition, literacy, socialization and overall school readiness. However, these programs made use of costly otoacoustic emissions (OAE) technology, which may not be feasible in LMICs.

A recent study demonstrated that smartphone based hearing screening may provide a low-cost, accurate and efficient screening solution with specific application to school based screening [12]. Furthermore, with limited training, non-health personnel such as community health workers or ECD practitioners can successfully conduct such screenings, thereby reducing the demand on already limited ear and hearing health professionals [12,13].

In order to successfully implement ECD hearing screening programs, it is important to first determine the perception and knowledge of ECD practitioners regarding the importance of healthy hearing, the causes and effects of a hearing loss, identification and intervention for hearing loss as well ECD practitioner attitudes towards children affected. This will assist to identify practical steps required to facilitate its acceptance. A study conducted in Singapore revealed educational deficits amongst ECD practitioners in normal development and across a range of developmental and behavioral disorders [14]. This was true despite a positive attitude among ECD practitioners 
towards receipt of additional information and support to better prepare them to recognize and manage children with disabilities [14]. The presence of a childhood hearing loss may easily be overlooked due to the fact that it is an invisible epidemic, which cannot be detected by a clinical examination. Additionally, childhood hearing loss often goes unnoticed due to factors including the misconception that a child is still too young, poor practitioner training and awareness, lack of resources, and cultural values and religious beliefs around inclusion of children with disabilities [15].

Establishing baseline information on the current knowledge and perceptions of ECD practitioners on hearing and hearing loss is an essential first step towards the success of ECD hearing screening programs. Subsequently appropriate and sufficient information on ear and hearing health care can ensure that ECD practitioners are better equipped to identify children affected by hearing loss, and to guide the access of services [16]. Unfortunately, limited knowledge currently exists on the views and knowledge of ECD practitioners on childhood hearing loss in LMICs. A recent study was conducted by Ehlert [17] in South Africa to determine the perceptions of primary school teachers regarding hearing loss. However this study focused on noise-induced hearing loss, revealing a need for hearing conservation programs in schools as well as training of teachers in order to be successful. The current study was therefore conducted to investigate the knowledge and attitude of ECD practitioners towards childhood hearing loss in a community representative of typical LMIC contexts.

\section{Method}

\subsection{Context}

The study was conducted in the community of Mamelodi, City of Tshwane, Gauteng, South Africa. Mamelodi is situated approximately $20 \mathrm{~km}$ east of the city. This township was established in 1951 and started with a mere 16 houses built for Black people that were removed from other areas according to the Group Areas Act. The unofficial population of Mamelodi is currently close to one million. Census indicates 110703 households within the community of which only $61 \%$ are formal dwellings [18]. 


\subsection{Subjects}

Purposive sampling was used to identify ECD centers and participants within the Mamelodi East and Mamelodi West communities. All personnel employed by these ECD centers, including principals and teachers, were invited to participate in this study. This created a sample that was representative of teachers from an informal urban developing South African community.

Each consenting participant was given adequate time to complete the questionnaire. A total of 82 participants completed the questionnaire.

\subsection{Questionnaire}

The questionnaire used to determine maternal views on hearing loss developed by Swanepoel \& Almec [4] was adapted for use with ECD teachers within the South African context. The adapted questionnaire consists of five added items to determine ECD practitioner's demographic information, with an additional 23 closed items requiring a choice of three responses: 'yes'; 'unsure'; or 'no'.

The existing questionnaire was adapted by adding four items to determine the general knowledge of ECD teachers towards healthy hearing and hearing loss. The items regarding the causes and risk factors of a hearing loss were simplified and adapted into five items for use with ECD practitioners. The four items regarding the identification and intervention for hearing loss were also adapted for use with ECD practitioners with an additional five items added to determine ECD practitioners' knowledge of the impact of hearing loss in the classroom. The items regarding superstitious cultural beliefs were omitted. Two items regarding attitudes towards hearing loss were adapted and one item was omitted. Additionally two items were added to determine ECD practitioner's attitude towards inclusion.

\subsection{Procedure and analysis}

All ECD centers within the target area were mapped. ECD principals and practitioners were thereafter approached at each ECD center and asked to participate in the study after which a date was set for data collection. On the 
test date, ECD personnel at their respective center were provided with an information leaflet attached to the developed questionnaire. Questionnaires were administered by a team member of a non-profit organization working in the community ECD's. The administrator was fluent in English and the African languages used by the community to ensure that the participants understood all the information and what was required of him/her. Participants were given the opportunity to ask for clarification. All questionnaires were completed anonymously and took approximately 10 minutes to complete.

The data collected was coded into quantitative data in MS Excel (2011). Responses were assigned the following scores: yes=1; unsure=2; no=3. All responses were analyzed descriptively by making use of frequency distributions, averages and standard deviations. Fisher's exact test was used to determine if gender and formal ECD training had an effect on individual survey items. Additionally, results of each question were totaled to get a score of participants' knowledge (i.e. the lower the score, the better a participants knowledge). Linear regression analysis was conducted to determine the effect of age, gender, formal ECD training, and length of experience on participants' overall knowledge.

\section{Results}

From the 82 questionnaires administered, one participant did not provide any of the demographic information requested. Of the remaining 81 respondents, $93 \%$ were female and $7 \%$ were male. Participants' ages ranged from 19 years to 61 years (mean=36.9; range=42). Participants' home languages covered all 11 official languages of South Africa, however the majority spoke Zulu (25\%), Sotho (21.3\%), Northern Sotho (20\%) and Ndebele (7.5\%).

Five participants did not report a qualification (i.e. did not respond to this question). Of the remaining 76 participants, $47.4 \%(n=36)$ reported having a high school certificate, $34.2 \%(n=26)$ received a higher certificate or diploma and $1.3 \%(n=1)$ received a degree in education. Length of experience ranged from one to 25 years (mean 7.6; SD 5.424; range=24). 
Table 1. Distribution of ECD personnel responses (\%) on childhood hearing loss

\begin{tabular}{|c|c|c|c|c|}
\hline \multirow[b]{2}{*}{ Questions } & \multicolumn{3}{|c|}{ Responses (\%) } & \multirow[t]{2}{*}{ Mean \pm SD } \\
\hline & Yes & Unsure & No & \\
\hline \multicolumn{5}{|l|}{ General } \\
\hline 1. Worked with a child with hearing loss & 35.4 & 20.7 & 43.9 & $2.09 \pm 0.892$ \\
\hline 2. Child with hearing loss in current ECD center & 29.3 & 32.9 & 37.8 & $2.09 \pm 0.82$ \\
\hline 3. Hearing loss is an important problem & 86.4 & 12.3 & 1.2 & $1.15 \pm 0.391$ \\
\hline 4. Healthy hearing is important & 90.1 & 9.9 & 0 & $1.10 \pm 0.300$ \\
\hline \multicolumn{5}{|l|}{ Knowledge: Causes/Risk Factors } \\
\hline 5. Children can be born with a hearing loss & 84.1 & 15.9 & 0 & $1.16 \pm 0.367$ \\
\hline 6. Certain illnesses can cause a hearing loss & 69.5 & 23.2 & 7.3 & $1.38 \pm 0.621$ \\
\hline 7. Ear infection can cause a hearing loss & 80.2 & 16.0 & 3.7 & $1.23 \pm 0.507$ \\
\hline $\begin{array}{l}\text { 8. Hearing loss can affect some children more } \\
\text { than others }\end{array}$ & 61.3 & 26.3 & 12.5 & $1.51 \pm 0.711$ \\
\hline 9. Hearing loss is common in young children & 51.3 & 45.0 & 3.8 & $1.53 \pm 0.573$ \\
\hline \multicolumn{5}{|l|}{ Knowledge: Identification \& Intervention } \\
\hline 10. Hearing loss can be identified at any age & 69.5 & 26.8 & 3.7 & $1.34 \pm 0.549$ \\
\hline $\begin{array}{l}\text { 11. Children (3-6 years of age) can be } \\
\text { accurately diagnosed with a hearing loss }\end{array}$ & 37.0 & 28.4 & 34.6 & $1.98 \pm 0.851$ \\
\hline 12. Hearing loss can be treated & 69.5 & 30.5 & 0 & $1.30 \pm 0.463$ \\
\hline 13. Children with hearing loss can attend school & 81.5 & 14.8 & 3.7 & $1.22 \pm 0.500$ \\
\hline $\begin{array}{l}\text { 14. Children with hearing loss can have the } \\
\text { same educational opportunities as normal } \\
\text { hearing children }\end{array}$ & 64.6 & 20.7 & 14.6 & $1.50 \pm 0.741$ \\
\hline $\begin{array}{l}\text { 15. Hearing loss impacts listening in the } \\
\text { classroom }\end{array}$ & 67.5 & 23.8 & 8.8 & $1.41 \pm 0.650$ \\
\hline 16. Hearing loss impacts speech and language & 58.8 & 32.5 & 8.8 & $1.50 \pm 0.656$ \\
\hline 17. Hearing loss impacts reading & 54.5 & 26.0 & 19.5 & $1.65 \pm 0.791$ \\
\hline 18. Hearing loss impacts behavior & 63.6 & 22.1 & 14.3 & $1.51 \pm 0.737$ \\
\hline 19. Hearing loss impacts interaction with peers & 73.7 & 15.8 & 16.5 & $1.37 \pm 0.670$ \\
\hline \multicolumn{5}{|l|}{ Attitudes } \\
\hline 20. Would like children to have a hearing test & 88.3 & 11.7 & 0 & $1.12 \pm 0.323$ \\
\hline $\begin{array}{l}\text { 21. Would include children with hearing loss in } \\
\text { the classroom/ECD }\end{array}$ & 61.0 & 31.2 & 7.8 & $1.47 \pm 0.640$ \\
\hline $\begin{array}{l}\text { 22. Children with hearing loss should be } \\
\text { referred to special schools }\end{array}$ & 67.5 & 22.1 & 10.4 & $1.43 \pm 0.677$ \\
\hline 23. Would like more information on hearing loss & 93.5 & 6.5 & 0 & $1.06 \pm 0.248$ \\
\hline
\end{tabular}

Results indicated that $35.4 \%(n=29)$ of respondents had previously worked with children with a hearing loss and $29.3 \%(n=24)$ are currently working with 
a child with a hearing loss (Table 1). The majority indicated that hearing loss (86.4\%) and healthy hearing (90.1\%) are important.

ECD personnel's knowledge regarding causes and risk factors for hearing loss was highest for congenital hearing loss (84.1\%) and ear infection (80.2\%). Additionally, a substantial number of ECD personnel (69.5\%) recognized that illnesses could cause a hearing loss.

The majority (69.5\%) of respondents indicated that hearing loss could be identified at any age, however, only $29.3 \%$ of these respondents indicated that children 3-6 years of age could be accurately diagnosed with a hearing loss. Respondents' knowledge of the impact of hearing loss in the classroom is illustrated in Figure 1.

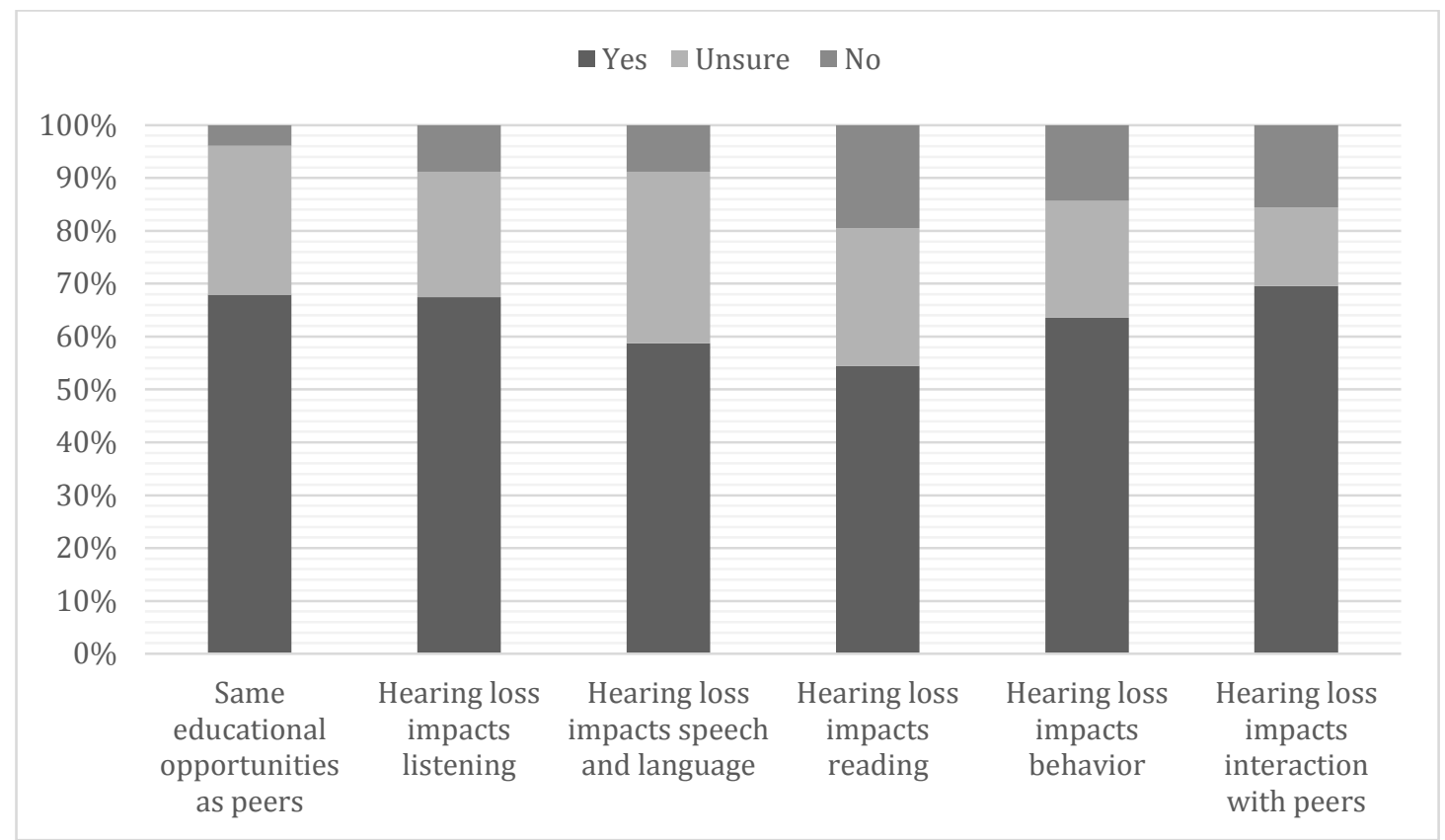

Figure 1. Distribution of responses regarding impact of hearing loss in the classroom

The majority of ECD personnel (61\%) were positive towards the inclusion of children with hearing loss in the classroom (Table 1), however a higher number $(67.5 \%)$ indicated that these children should be referred to special schools. The attitude of ECD personnel towards hearing tests was very positive (88.3\%) and almost all participants indicated that they wanted more information regarding childhood hearing loss (93.5\%). 
Formal ECD training had a significant effect on knowledge around illnesses that could cause a hearing loss, identification of hearing loss at any age and hearing loss impacting listening in the classroom $(p<0.05$; Fishers exact). Linear regression analysis indicated that gender, age and formal ECD training had no significant effect on participants overall knowledge and attitudes regarding childhood hearing loss $(p>0.05)$. Only ECD personnel's duration of experience had a significant effect on overall knowledge and attitudes towards childhood hearing loss $(p<0.05 ; F(1,53)=8.68)$.

\section{Discussion}

Contextual evidence on knowledge and perceptions around childhood hearing loss by ECD practitioners is essential to ensure acceptance and support of hearing screening programs in these facilities. This study is the first to provide a baseline of current ECD practitioner knowledge and attitudes towards hearing health within a poor LMIC community setting. Responses regarding ECD practitioner's overall knowledge and attitudes towards hearing health were generally positive. Most ECD practitioners recognized that hearing health in children is important and displayed a positive attitude towards hearing screenings. This may be indicative of ECD practitioner readiness for the introduction and implementation of ECD hearing screening programs within LMICs [4].

Knowledge of ECD practitioners regarding etiological factors for hearing loss was generally favorable. The majority of ECD practitioners correctly identified genetics $(84.1 \%)$ and ear infections (80.2\%) as etiological factors of hearing loss. These ECD practitioners may have previously worked with children with ear infections as the incidence of acute otitis media and otitis media with effusion is high in LMICs [7,19,20]. Additionally, more than $60 \%$ recognized that certain illnesses could cause a hearing loss and that the effects of hearing loss could vary.

ECD practitioner knowledge scores regarding the identification of hearing loss demonstrated some uncertainty with $69.5 \%$ indicating that hearing loss could be identified at any age, whilst only a third (29.3\%) of these respondents 
thought children 3-6 years of age can be accurately diagnosed. Knowledge around screening and diagnostic audiological procedures was limited considering available methods to detect hearing loss in children of any age $[1,21]$. Various reasons could be attributed to this gap in knowledge including the fact that LMICs have a lack of EHDI programs, no systematic ECD screening programs, limited school screening programs, and hearing services are mostly unavailable in public health care systems which majority of the population rely on $[6,9,22]$.

The majority of participants (81.5\%) were knowledgeable regarding the attendance of schools by children with a hearing loss, however a greater number of ECD practitioners felt that these children should be referred to special schools rather than be included in a mainstream classroom. According to a review conducted by Avramidis and Norwich's [23], ECD practitioners may be positive towards the general philosophy of inclusion, however they hold differing attitudes towards school placements depending on the nature of the child's disability. ECD practitioners may be more willing to include students with mild sensory impairments than students with more complex needs [23]. Furthermore, almost all ECD practitioners indicated the need for more information on hearing loss, which, if provided, may improve willingness to include children with a hearing loss in a mainstream setting.

Although most ECD practitioners were knowledgeable about the impact of hearing loss in the classroom, a significant amount of ECD practitioners $(37.2 \%)$ were unsure or responded incorrectly. These responses highlight a need for increased emphasis regarding the educational impact of hearing loss on learners in teacher education programs. Resources like the WHO primary ear and hearing care training manuals have been recommended for training community health workers in LMICs to educate teachers about hearing loss, it's impact and management, as well as to encourage them to include this in their teaching programs [16].

Other influences reported to have an effect on practitioner knowledge and attitudes includes teacher-related variables such as gender, age, length of 
teaching experience, experience of contact, beliefs, socio-political views, as well as educational environmental-related variables, such as the support from specialists [23]. The current study found this to be true for length of teaching experience, with significantly higher scores in both knowledge and attitude by respondents who reported more years of experience. Formal ECD training was also found to have a significantly positive effect on knowledge scores however, this was limited to illnesses as a cause of hearing loss, the ability to identify hearing loss at any age, and the impact of hearing loss on listening in the classroom.

\section{Conclusion}

Within LMICs, ECD practitioner's knowledge and attitudes around hearing and hearing loss are important for the successful implementation of screening programs, particularly within these poorer settings where ECD centers may serve as the first point of accesss for screening. The current study found gaps in knowledge regarding methods for the identification of hearing loss as well as the impact of hearing loss in the classroom. Attitudes towards inclusion of children with a hearing loss may be improved by providing information and guidelines to ECD practitioners on how to identify and support a child with a hearing loss in the classroom. Length of experience was found to have a significant influence on knowledge and attitude scores of ECD practitioners. Overall, ECD practitioner's knowledge and attitudes from this LMIC context was favourable, demonstrating a general readiness for implementation of hearing screening programs within ECD facilities.

\section{Acknowledgements}

We would like to thank all the participants involved with this study, including the team leaders and community health workers of the community of Mamelodi.

\section{Conflict of interests}

The author(s) have no conflicts of interest to declare. 


\section{Funding}

The financial assistance of the National Institute for the Humanities and Social Sciences, in collaboration with the South African Humanities Deans Association towards this research is hereby acknowledged. Opinions expressed and conclusions arrived at are those of the author and are not necessarily to be attributed to the NIHSS and SAHUDA.

\section{References}

1. American Academy of Audiology (AAA), American Academy of Audiology Childhood Hearing Screening Guidelines, 2011. Available from:

http://www.cdc.gov/ncbddd/hearingloss/documents/aaa_childhoodhearing-guidelines_2011.pdf (accessed on 01.09.17).

2. Joint Committe on Infant Hearing $(\mathrm{JClH})$, Year 2007 position statement: principles and guidelines for early hearing detection and intervention programs, Pediatrics. 120 (2007) 898-921. doi: 10.1542/peds.2007-2333

3. C. Mathers, A.Smith, M. Concha, Global burden of hearing loss in the year 2000, World Health Organ. (2000) 1-30. Available from: http://www.who.int/healthinfo/statistics/bod_hearingloss.pdf (accessed on 10.03.17).

4. D. W. Swanepoel, N. Almec, Maternal views on infant hearing loss and early intervention in a South African community, Int. J. Audiol. 47 (2008) S44-S48. doi: 10.1080/14992020802252279

5. B. O. Olusanya, V. E. Newton, Global burden of childhood hearing impairment and disease control priorities for developing countries, Lancet. 369 (2007) 1314-1317.

6. D. W. Swanepoel, C. Störbeck, P. Friedland, Early hearing detection and intervention in South Africa, Int. J. Pediatr. Otorhinolaryngol. 73 (2009) 783-786. doi: 10.1016/j.ijporl.2009.01.007.

7. World Health Organization (WHO), Newborn and infant hearing screening, Current issues and guiding principals for action, Outcomes of a WHO informal consultation held at WHO headquarters, Geneva, Switzerland, 09-10 November 2009, WHO, 2010. 
8. J. Bamford, H. Fortnum, K. Bristow, J. Smith, G. Vamvakas, L. Davies, et al., Current practice, accuracy, effectiveness and cost-effectiveness of the school entry hearing screen, Health Technol. Assess. 11 (2007).

9. World Health Organization(WHO), Deafness and hearing loss, 2014. Available from: http://www.who.int/mediacentre/factsheets/fs300/en/ (accessed: 10.03.17).

10. Department of Social Development, Integrated national strategy on support services to children with disabilities, 2009. Available from www.hsrc.ac.za/en/research-data/ktree-doc/1672 (accessed 20.04.17).

11.W. D. Eiserman, L. Shisler, T. Foust, J. Buhrmann, R. Winston, K. R. White, Screening for hearing loss in early childhood programs, Early Child. Res. Q. 22 (2007) 105-117. doi: 10.1016/j.ecresq.2006.09.001.

12.F. Mahomed-Asmail, D. W. Swanepoel, R. H. Eikelboom, H. C. Myburgh, J. W. Hall, Clinical validity of hearScreen ${ }^{\mathrm{TM}}$ smartphone hearing screening for school children, Ear Hearing. 37 (2016), e11e17. doi: 10.1097/AUD.0000000000000223.

13.S. Yousuf Hussein, D. W. Swanepoel, L. Biagio de Jager, H. C. Myburgh, R. H. Eikelboom, J. Hugo, Smartphone hearing screening in mHealth assisted community-based primary care, J. Telemed. Telecare. 22 (2016), 405-412. doi: 10.1177/1357633X15610721.

14. W. B. Lian, S. H. Ying, S. C. Tean, D. C. Lin, Y. C. Lian, H. L. Yun, Preschool teachers' knowledge, attitudes and practices on childhood developmental and behavioral disorders in Singapore, J. Paediatr. Child. Health. 44 (2008) 187-194. doi: 10.1111/j.14401754.2007.01231.x

15. H. Ebrahim, J. Seleti, A. Dawes, Learning begins at birth: Improving access to early learning, South African Child Gauge, 2013, 66-71.

16. World Health Organization (WHO), Community-Based Rehabilitation Promoting ear and hearing care through CBR, Geneva, Switzerland, WHO, 2012.

17.K. Ehlert, Perceptions of public primary school teachers regarding noise-induced hearing loss in South Africa, S. Afr. J. Commun. Disorders. 64 (2017), e1-e12. doi: 10.4102/sajcd.v64i1.185

18. Statistics South Africa (Stats SA), Mamelodi, 2011. Available from: 
http://www.statssa.gov.za/?page_id=4286\&id=11377

(accessed: 05.10.17)

19. L. Biagio, D. W. Swanepoel, C. Laurent, T. Lundberg, Paediatric otitis media at a primary healthcare clinic in South Africa, S. Afr. Med. J. 104 (2014). doi: 10.7196/SAMJ.7534.

20. L. Monasta, L. Ronfani, F. Marchetti, M. Montico, L. V. Brumatti, A. Bavcar, et al., Burden of disease caused by otitis media: Systematic review and global estimates, PLoS One. 7 (2012). doi: 10.1371/journal.pone.0036226.

21.M. Cunningham, E. O. Cox, Hearing assessment in infants and children: Recommendations beyond neonatal screening, Pediatrics, 111 (2009) 436-440. doi: 10.1542/peds.2009-1997.

22. World Health Organization (WHO), Multi-country assessment of national capacity to provide hearing care, 2013. Available from: http://www.who.int/pbd/publications/WHOReportHearingCare_Englishw eb.pdf (accessed: 30.04.17).

23.E. Avramidis, B. Norwich, Teachers' attitudes towards integration/inclusion: A review of the literature, Eur. J. Spec. Needs. Educ. 17 (2002) 129-147. doi: 10.1080/08856250210129056. 